\title{
Antibacterial Additive for Polystyrene Based on Silver Nanoparticles Supported on Titanium Dioxide
}

\author{
Miguel A. Waldo-Mendoza, ${ }^{1,2}$ Lucía Martínez-Jothar, ${ }^{3}$ Socorro Oros-Ruiz, ${ }^{4}$ \\ E. G. Villabona-Leal, ${ }^{3}$ Luis Manuel Céspedes-Covarrubias, ${ }^{2}$ Zoe V. Quiñones-Jurado, ${ }^{2}$ \\ Eduardo Ortega, ${ }^{5}$ and Elías Pérez ${ }^{3}$ \\ ${ }^{1}$ Facultad de Ciencias Químicas, Universidad Autónoma de San Luis Potosí, Av. Manuel Nava No. 6, Zona Universitaria, \\ 78290 San Luis Potosí, SLP, Mexico \\ ${ }^{2}$ Innovación y Desarrollo en Materiales Avanzados, A.C., Grupo Polynnova, Carretera San Luis Potosí-Guadalajara No. 1510, \\ Nivel 3, Despacho 13, Fraccionamiento Lomas del Tecnológico, 78211 San Luis Potosí, SLP, Mexico \\ ${ }^{3}$ Instituto de Física, Universidad Autónoma de San Luis Potosí, Álvaro Obregón 64, 78000 San Luis Potosí, SLP, Mexico \\ ${ }^{4}$ Departamento de Química, Universidad Autónoma Metropolitana-Iztapalapa, 09340 Ciudad de México, Mexico \\ ${ }^{5}$ Departamento de Física, Tecnológico de Monterrey, 64849 Monterrey, NL, Mexico
}

Correspondence should be addressed to Elías Pérez; elias@ifisica.uaslp.mx

Received 1 July 2016; Accepted 20 October 2016

Academic Editor: Ing Kong

Copyright (C) 2016 Miguel A. Waldo-Mendoza et al. This is an open access article distributed under the Creative Commons Attribution License, which permits unrestricted use, distribution, and reproduction in any medium, provided the original work is properly cited.

\begin{abstract}
Silver nanoparticles supported on titanium dioxide nanoparticles $\left(\mathrm{Ag} / \mathrm{TiO}_{2}\right)$ were incorporated and evaluated as antibacterial additive for polystyrene materials. These particles were synthesized using a deposition-precipitation method by adding silver nitrate as metallic precursor, sodium hydroxide as reducing agent, and commercial $\mathrm{TiO}_{2}$ (P25) as support. Rectangular pieces of polystyrene (PS) containing 100, 300,500, and $700 \mathrm{ppm}$ (wt.\%) of the additive were made using an extrusion-injection molding process, and they were evaluated for their antibacterial properties against Escherichia coli using the Pour Plate method. Particles were distributed on the PS surface, and PS pieces presented a good antibacterial efficiency at 100, 300, and 500 ppm and decreased for $700 \mathrm{ppm}$ due to an additive agglomeration on the PS surface. These results validate the antibacterial properties of $\mathrm{Ag} / \mathrm{TiO}{ }_{2}$, determine a concentration limit at which the additive is well distributed on the PS surface, and assess the importance of Ag in this system.
\end{abstract}

\section{Introduction}

Antimicrobials are natural or synthetic chemical compounds that kill or suppress the growth of viruses, bacteria, and/or fungi. Activity against bacteria and fungi is currently of major interest in the plastic industry as it promotes preservation and increased shelf life of the goods [1]. Polystyrene is an easily moldable material for injection, blown, extrusion, and thermoformed processes. It is also a material with wide applications in electrodomestics and food and pharmaceutical containers. These applications made polystyrene a suitable material to test the $\mathrm{Ag} / \mathrm{TiO}_{2}$ composite as an antimicrobial agent [2].
The use of silver based antimicrobials has dramatically increased in the plastic industry due mainly to low toxicity to humans as well as long-lasting efficacy. Silver (Ag) nanoparticles can be easily synthesized and incorporated into polymeric matrices, making it possible to use them as additives against bacterial action. The antibacterial activity of silver nanoparticles relies on several mechanisms, including damage to the cell wall, increase in the permeability and leakage of intracellular substances, alteration in the expression of envelope proteins and heat shock proteins, dissipation of the proton motive force, collapse of the plasma membrane potential, and decrease of intracellular ATP [3, 4]. Additionally, the liberation of silver ions increases the 
bactericidal effect since they are known to participate in the generation of reactive oxygen species, alter proteins by interacting with thiol groups, and induce DNA condensation leading to the loss of bacterial replication $[5,6]$.

On the other hand, titanium dioxide $\left(\mathrm{TiO}_{2}\right)$ is an additive currently used in the plastic industry that can also exhibit photocatalytic properties when it is exposed to UV radiation leading to the generation of electrons and holes that are able to oxidize water and hydroxide ions to produce highly reactive hydroxyl radicals capable of decomposing bacterial cell membranes [7]. These properties of $\mathrm{TiO}_{2}$ can also be enhanced by the presence of silver nanoparticles on its surface $\left(\mathrm{Ag} / \mathrm{TiO}_{2}\right)$. For instance, photocatalytic degradation of rhodamine $\mathrm{B}$ and 2,4,6-trichlorophenol was more effective using $\mathrm{Ag} / \mathrm{TiO}$ than $\mathrm{TiO}_{2}$ alone, and $\mathrm{TiO}_{2}$ films that contained silver exhibited a higher antibacterial activity against Escherichia coli than $\mathrm{TiO}_{2}$ by itself [8-10]. The use of $\mathrm{Ag} / \mathrm{TiO}_{2}$ nanoparticles is presented in this work as a potential antibacterial additive given the properties of the individual components. They were obtained by simultaneous synthesis and deposition of $\mathrm{Ag}$ nanoparticles on the $\mathrm{TiO}_{2}$ particle surface through a deposition-precipitation method, which allows for a controlled particle growth [11]. The materials generated by this method present higher photo oxidizing activities than those synthesized using other procedures (colloidal deposition, photodeposition, impregnation, etc.) $[12,13]$. However, the size, shape, and metal concentration on the surface of the support are sensitive to parameters such as the $\mathrm{pH}$ of the reaction mixture [14-16]. For that reason, in this study we have synthesized $\mathrm{Ag} / \mathrm{TiO}_{2}$ varying the $\mathrm{pH}$ and keeping constant all other synthesis conditions. We have found that while nanoparticle size is not affected by $\mathrm{pH}$ variations, the presence of $\mathrm{Ag}$ on the $\mathrm{TiO}_{2}$ surface is sensitive to this difference, being greater at $\mathrm{pH}$ 9. $\mathrm{Ag} / \mathrm{TiO}_{2}$ nanoparticles were then incorporated into PS through an extrusion-injection process, resulting in rectangular pieces containing 100, 300, 500, and $700 \mathrm{ppm}$ (wt.) of $\mathrm{Ag} / \mathrm{TiO}_{2}$, with respect to the PS content. The PS containing this additive displays antibacterial properties against Escherichia coli even in the absence of light. As discussed, this property is directly related to the presence of the $\mathrm{Ag} / \mathrm{TiO}_{2}$ on the PS surface and also to the effectivity of the $\mathrm{Ag}$ in this additive.

\section{Experimental}

2.1. Silver Nanoparticles Synthesis and Deposition on $\mathrm{TiO}_{2}$. $\mathrm{Ag} / \mathrm{TiO}_{2}$ nanoparticles were synthesized in the absence of light through a deposition-precipitation method using silver nitrate (Fermont) as metallic precursor, sodium hydroxide (Caledon Laboratories LTD) as reducing agent, and $\mathrm{TiO}_{2}$ Degussa P25 (Degussa Corporation/Pigments Group) as support. Briefly, an aqueous solution of silver nitrate containing $1.5 \mathrm{wt} . \%$ of silver on $\mathrm{TiO}_{2}$ was added to an aqueous suspension of $\mathrm{TiO}_{2}$. The mixture was heated to $80^{\circ} \mathrm{C}$ under vigorous stirring and the $\mathrm{pH}$ was adjusted to 9,11 , or 12 using sodium hydroxide. Heating and mixing were held for two hours, then the solution was centrifuged (10000 rpm), and the precipitate was washed with water at $50^{\circ} \mathrm{C}$. After a second centrifugation, the solid was dried in an oven at $80^{\circ} \mathrm{C}$ for 12 hours, ground, and stored in the dark.

2.2. Nanoparticle Characterization. The size and shape of $\mathrm{Ag} / \mathrm{TiO}_{2}$ particles were characterized by a JEOL JEM1230 TEM operated at $100 \mathrm{KV}$ in the bright field imaging mode. Particle size and size distributions were calculated by measuring around 200 metal particles. SEM-EDX analysis was performed on a Philips FEI microscope model XL-30PW6630/01 operated at $20 \mathrm{~kW}$.

2.3. Extrusion of Polystyrene with $\mathrm{Ag} / \mathrm{TiO}_{2}$. A mixture of $\mathrm{Ag} / \mathrm{TiO}_{2}$ and PS was injected using an Injection Molding Machine Battenfeld, Model LCMI in which the temperature of the barrel ranged between 190 and $210^{\circ} \mathrm{C}$. The temperature of the mold was $27^{\circ} \mathrm{C}$, the shoot volume was $43 \mathrm{cc}$, the screw speed was of $43 \mathrm{rpm}$, the pressure was $8.27 \mathrm{MPa}$, the cooling time was $15 \mathrm{~s}$, and the cycle consisted of $31 \mathrm{~s}$ in total. This process resulted in the production of $\mathrm{PS}-\mathrm{Ag} / \mathrm{TiO}$ rectangular pieces with dimensions of $100 \times 70 \times 3 \mathrm{~mm}$, which contained $100,300,500$, and $700 \mathrm{ppm}$ (wt.) of $\mathrm{Ag} / \mathrm{TiO}_{2}$ with respect to the PS content.

2.4. Polystyrene-Ag/TiO 2 Surface Characterization. An Atomic Force Microscope (AFM) Multimode with a NanoScope IIIa controller (Veeco Metrology Group, Santa Barbara, USA) was used in intermittent contact mode using nonconductive silicon rectangular cantilevers (Bruker MPP-11120, tip radius $\sim 8 \mathrm{~nm}$ ) with a length of $125 \mu \mathrm{m}$ and nominal frequency of $300 \mathrm{KHz}$ to obtain images in phase contrast, which allowed the study of the dispersion of $\mathrm{Ag} / \mathrm{TiO}_{2}$ nanoparticles on the PS surface. The images were processed by using the NanoScope Analysis software (version 1.40, Bruker Corporation). The presence of the nanoparticles on the PS surface was confirmed by analyzing the phase histogram from the raw data matrix acquired. The percentage of the PS surface covered by $\mathrm{Ag} / \mathrm{TiO}_{2}$ was estimated as the ratio between the areas under the peaks observed in the phase distribution of the samples:

$$
\% \text { of PS surface covered }=\left(\frac{A_{\mathrm{NP}}}{A_{\mathrm{PS}}+A_{\mathrm{NP}}}\right) 100 \text {, }
$$

where the subindexes PS and NP refer to the PS surface and the nanoparticles, respectively. Additionally, the dissipated energy during the tip-surface interaction can be calculated from the change in the oscillation amplitude and phase lag $\phi$, using the equation:

$$
E_{\text {dis }}=\left(\sin \varphi-\frac{A}{A_{0}}\right) \frac{\pi k A A_{0}}{Q}
$$

in which $A$ is the amplitude during testing, $A_{0}$ is the free amplitude, $k$ is the force constant of the cantilever, and $Q$ is the quality factor [17]. This dissipative energy is used to distinguish different components on the material surface [1820]. 


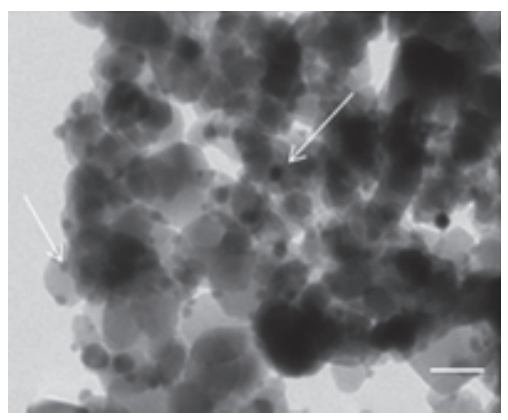

(a)

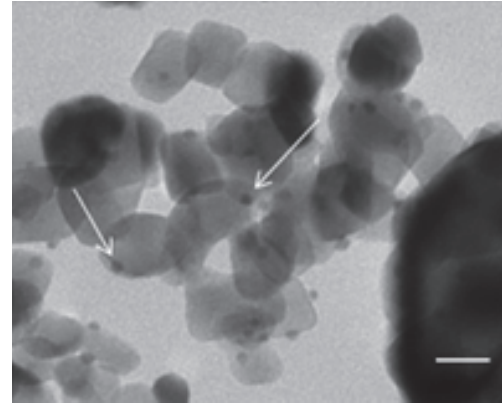

(b)

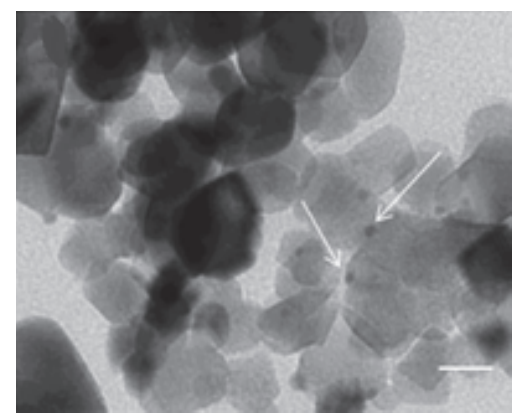

(c)

FIGURE 1: TEM images of silver nanoparticles (arrows) deposited on $\mathrm{TiO}_{2}$, synthesized at pH 9 (a), pH 11 (b), and pH 12 (c). At all the pH values showed, nanoparticles presented the same form with an average size ranging from 5.6 to $6.0 \mathrm{~nm}$, while the average size of $\mathrm{TiO}_{2}$ was $35 \pm 10 \mathrm{~nm}$. At pH 9, Ag nanoparticles were more abundant. The scale line represents $20 \mathrm{~nm}$.

2.5. Antibacterial Activity of $\mathrm{PS}-\mathrm{Ag} / \mathrm{TiO}_{2}$ Samples. Antibacterial tests, performed on Escherichia coli ATCC 25922, were conducted as follows: $400 \mu \mathrm{L}$ of a bacterial suspension containing a total of $4 \times 10^{5}$ colony forming units was placed at the center of the test surface that had been previously cut to a square with dimensions of $50 \times 50 \mathrm{~mm}$. The suspension on the PS surface was covered using a flexible film square $(40 \times 40 \mathrm{~mm})$ and the sample was incubated in a chamber (relative humidity $>90 \%$ ), in the dark, at $35 \pm 1{ }^{\circ} \mathrm{C}$ for $24 \pm 1$ hours. It must be kept in mind that under this condition (incubation in the absence of light) it is unlikely that $\mathrm{TiO}_{2}$ will exhibit antibacterial effect, since this is dependent on its photocatalytic properties. Therefore, antibacterial activity of the sample will only be attributed to the action of silver. After the incubation, the sample was placed on a plastic bag and $10 \mathrm{~mL}$ of Tryptic Soy Broth (Bioxon) was added and used to wash the sample in views to recover the bacteria present in it. The bacterial count was performed using the Pour Plate method: from the wash, dilutions ranging from $10^{-1}$ to $10^{-10}$ were made in Phosphate Buffer Saline and $1 \mathrm{~mL}$ of each dilution was placed in a petri dish to which liquid Plate Count Agar (Bioxon) was added. The sample was homogenized and after the agar hardened it was incubated at $35 \pm 1^{\circ} \mathrm{C}$ for 48 hours. Counting was performed in plates containing between 30 and 300 colonies.

\section{Results and Discussion}

3.1. Characterization of $\mathrm{Ag} / \mathrm{TiO}_{2}$ Nanoparticles. The size of silver nanoparticles was obtained from the analysis of TEM images as presented in Figure 1. The silver nanoparticles synthesized at $\mathrm{pH}$ of 9,11 , and 12 , using $1.5 \mathrm{wt} \%$ of $\mathrm{Ag} / \mathrm{TiO}_{2}$, are presented in Figures 1(a), 1(b), and 1(c), respectively. The average Ag particle sizes obtained were $5.7 \pm 1.6 \mathrm{~nm}$, $6.0 \pm 1.9 \mathrm{~nm}$, and $5.6 \pm 1.4 \mathrm{~nm}$, respectively. All nanoparticles displayed approximately the same shape regardless of the $\mathrm{pH}$, even though the influence of $\mathrm{pH}$ on nanoparticle assembly, size, and distribution was previously reported [21-23]; in our case for the different $\mathrm{pH}$ evaluated, it did not seem to have a determining effect on the particle size. The effect of metal loading of $\mathrm{Ag}$ on $\mathrm{TiO}_{2}$ as confirmed by SEM-EDX analysis and scanning electron micrography is presented in Figure 2(a) where the following can be observed the presence of agglomerates of $\mathrm{Ag} / \mathrm{TiO}_{2}$ composites on the surface of the polymer and in Figure 2(b) the EDS analysis to determine metal loadings, showing that the effect of $\mathrm{pH}$ did not have a significant effect on the amount of silver deposited: $1.28 \pm 0.3$, $1.40 \pm 0.34$, and $1.37 \pm 0.21 \mathrm{wt} \%$, respectively, for $\mathrm{pH} 9, \mathrm{pH}$ 11 , and $\mathrm{pH} 12$.

3.2. AFM Characterization of $\mathrm{PS}-\mathrm{Ag} / \mathrm{TiO} \mathrm{O}_{2}$ Samples. Figure 3 presents AFM height, phase contrast, and energy dissipation images (columns (a), (b), and (c), resp.) of a PS matrix containing 100, 300, 500, and $700 \mathrm{ppm}$ of $\mathrm{Ag} / \mathrm{TiO}_{2}$, acquired within the month of its fabrication. These images showed distinctive local zones produced by the presence of nanoparticles at the surface of the material which contrasts with the reference sample that consists of pure PS. The presence of the nanoparticles on the PS surface is expected due to their difference in solubility: while PS is hydrophobic in nature and nanoparticles are hydrophilic, this difference induces the presence of $\mathrm{Ag} / \mathrm{TiO}_{2}$ on the PS surface. In addition, the temperatures used for the injection of PS and $\mathrm{Ag} / \mathrm{TiO}_{2}$ could facilitate the migration of the particles into the surface [24].

Figure 3 also highlights that the presence of agglomerates of the antibacterial additive reaches a maximum at a concentration of $700 \mathrm{ppm}$. This last result is not surprising since nanoparticles tend to agglomerate due to the large interparticle forces that exist between them (i.e., van der Waals forces) $[25,26]$.

The dispersion of these nanoparticles on the PS surface is corroborated by the analysis of the phase histograms shown in Figure 4. As observed, there are three histograms with a bimodal distribution (at 100,300, and $700 \mathrm{ppm}$ ) and two with a unimodal distribution (at 0 and $500 \mathrm{ppm}$ ). The existence of two modes exhibits a poor distribution of the additive into the matrix surface, while the unimodal distribution coincides with the image from the PS alone and the image from the sample with the best nanoparticle distribution on the surface. In consequence, the nanoparticle dispersion on the PS surface was favored at low concentrations of $\mathrm{Ag} / \mathrm{TiO}_{2}$, 


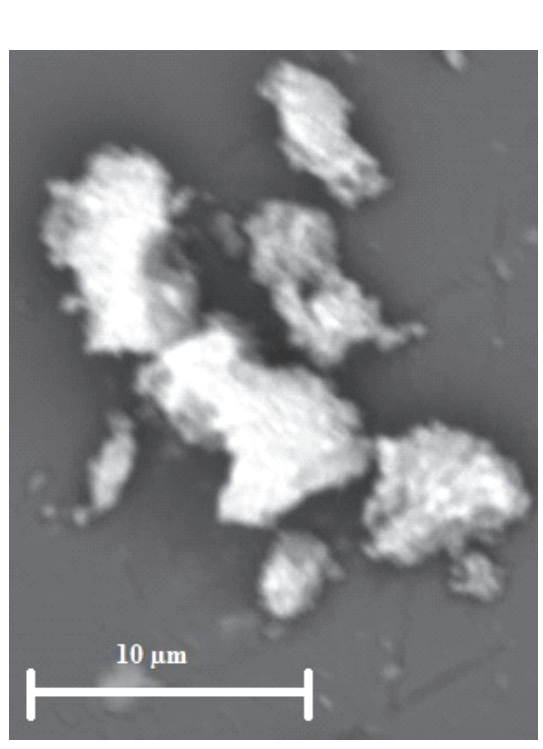

(a)

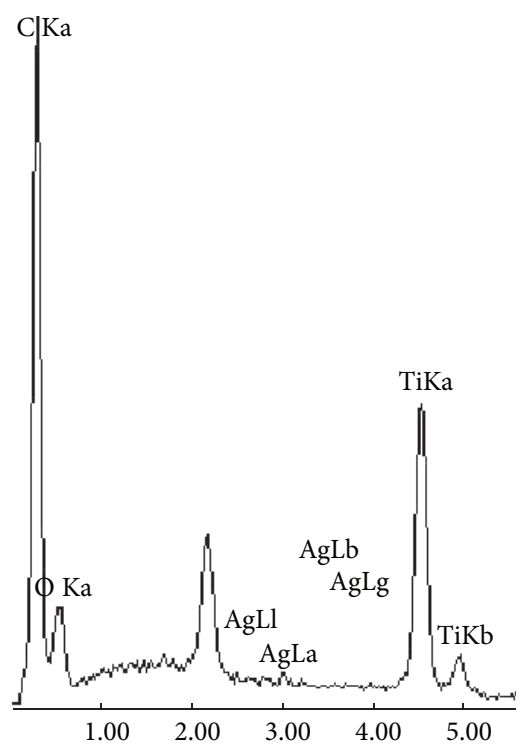

(b)

Figure 2: (a) SEM image of $\mathrm{Ag} / \mathrm{TiO}_{2}$ composite on polystyrene; (b) EDX spectrum of $\mathrm{Ag} / \mathrm{TiO}_{2}$ composites.

with the most homogenous distribution of nanoparticles achieved at $500 \mathrm{ppm}$. In order to confirm the presence of the nanoparticles on the PS surface, the energy dissipation of the cantilever's oscillation was calculated, to give the energy that we are losing each cycle of the tapping mode as that value will depend on the material, resulting in values between 29.2 and 44.0 aJ for the PS, in accordance with previous reports, and values between 8.8 and $21.4 \mathrm{aJ}$ for the regions affected by the nanoparticles [20]. This reduction in energy is expected for the nanoparticles given that they dissipate less energy and therefore indicate the dispersion of a harder additive $\left(\mathrm{Ag} / \mathrm{TiO}_{2}\right)$ into the surface of a softer (PS) matrix. This approach presents a nondestructive subsuperficial characterization technique that avoids heating, radiolysis, and degradation of the polymer matrix.

The percentage of surface coverage of the PS samples containing different amounts of $\mathrm{Ag} / \mathrm{TiO}_{2}$ was calculated from results presented in Figure 5, as described above. The values obtained were $54.7 \%, 52.3 \%, 89.3 \%$, and $23.1 \%$ for the samples containing 100, 300, 500, and $700 \mathrm{ppm}$. These values, related to the surface coverage, are a clear indicator of the expected antibacterial effects of these composites.

3.3. Antibacterial Activity of PS- $\mathrm{Ag} / \mathrm{TiO}_{2}$ Samples. Antibacterial activity was evaluated through the inoculation of $4 \times$ $10^{5}$ colony forming units of $E$. coli on the different PS plates containing $\mathrm{Ag} / \mathrm{TiO}_{2}$. The inoculation was followed by a $24 \pm 1$ hours of incubation. As shown in Figure 4, PS-Ag/ $/ \mathrm{TiO}_{2}$ pieces display different degrees of antibacterial activity compared to bare PS and said activity is directly related to the surface coverage of the PS samples with $\mathrm{Ag} / \mathrm{TiO}_{2}$. It is important to note that the PS test pieces inhibited bacterial growth by more than $80 \%$ at $\mathrm{Ag} / \mathrm{TiO}_{2}$ loadings of $100 \mathrm{ppm}, 300 \mathrm{ppm}$, and $500 \mathrm{ppm}$. The antibacterial activity of $\mathrm{Ag} / \mathrm{TiO}_{2}$ nanoparticles on PS could be the result of one or several of the antibacterial mechanisms mentioned above (see Section 1). On the other hand, a severe decrease in the antibacterial activity was observed for $\mathrm{Ag} / \mathrm{TiO}_{2} 700 \mathrm{ppm}$, indicating that there is a concentration limit beyond which the antibacterial effect of this additive is diminished. This is evidently related to the $\mathrm{Ag} / \mathrm{TiO}_{2}$ agglomerates formed at $700 \mathrm{ppm}$, which reduce the contact surface between the antibacterial composite and E. coli resulting in less bacterial death than for the other concentrations in which the nanoparticles are more evenly distributed on the PS surface. Taking into consideration this information and the data obtained from the AFM images, it is evident that the antibacterial effect of $\mathrm{Ag} / \mathrm{TiO}_{2}$ is more likely a result of its distribution in the surface of the PS, rather than of its bulk concentration.

\section{Conclusions}

An antibacterial additive based on $\mathrm{Ag} / \mathrm{TiO}_{2}$ nanoparticles was evaluated and validated using PS as plastic matrix. $\mathrm{Ag} / \mathrm{TiO}_{2}$ nanoparticles were mixed with the PS through an extrusion-injection process and nanoparticles were localized on the PS surface, as shown by AFM characterization. Indeed, the antibacterial effect was directly correlated with the presence of the $\mathrm{Ag} / \mathrm{TiO}_{2}$ nanoparticles on the PS surface. The antibacterial tests against $E$. coli were carried at 100, 300, 500 , and $700 \mathrm{ppm}$ (wt) of $\mathrm{Ag} / \mathrm{TiO}_{2}$, with respect to the PS content, in the absence of light to assess the effect of Ag in the antibacterial additive. At low concentrations (100, 300, and $500 \mathrm{ppm}$ ), bacterial growth inhibition was greater than $80 \%$, showing that $\mathrm{Ag} / \mathrm{TiO}_{2}$ has good antibacterial properties independently of the concentration values. However, agglomerates were observed at $700 \mathrm{ppm}$ accompanied by a diminishing antibacterial effect. This finding established a limit for the additive concentration that can be used for the production of antibacterial PS surfaces. The previous 

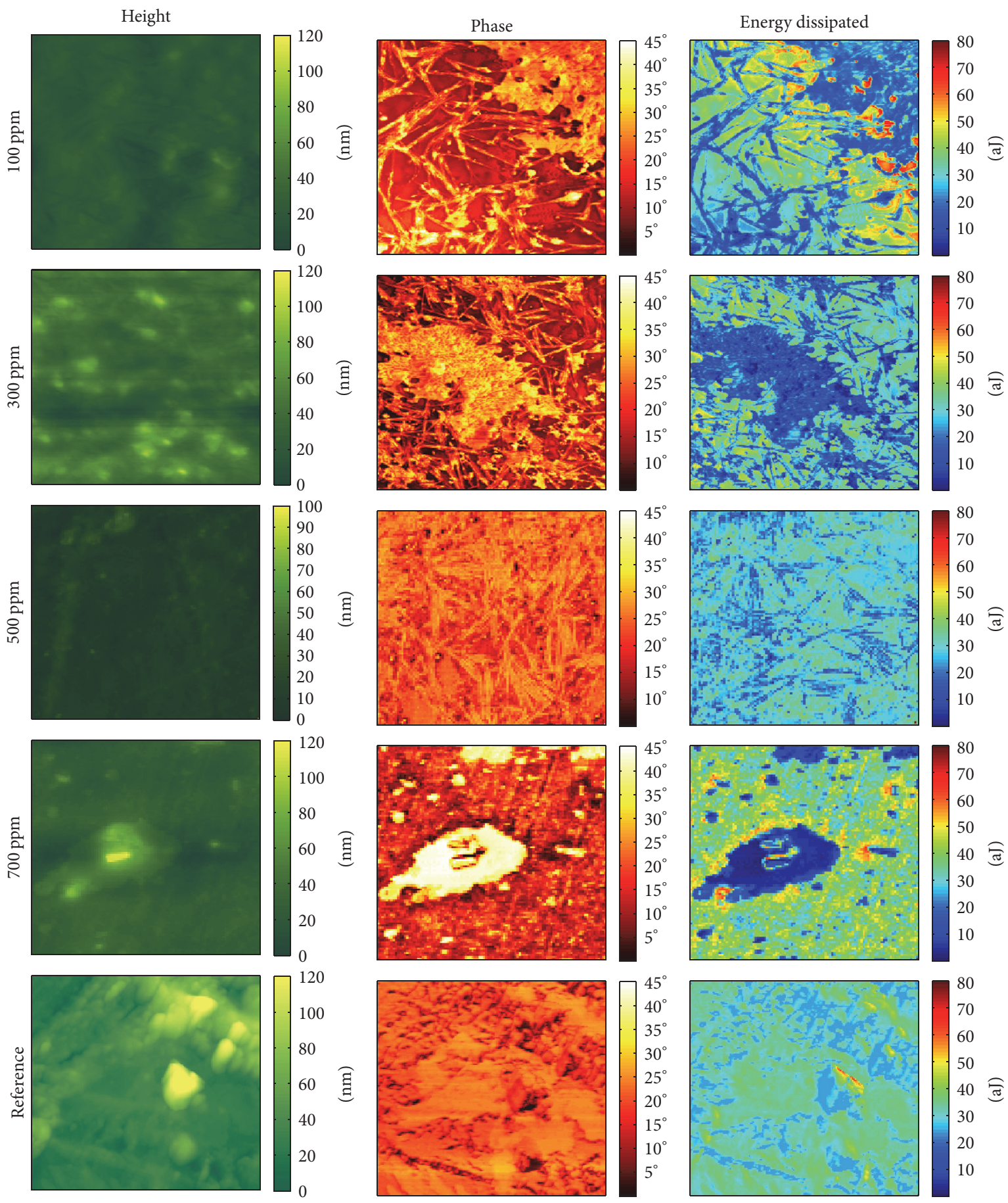

(a)

(b)

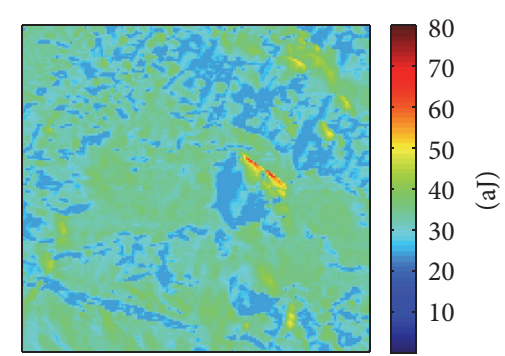

(c)

FIGURE 3: AFM height, phase contrast, and energy dissipation images of a PS matrix with different amounts of $\mathrm{Ag} / \mathrm{TiO}_{2}$ nanoparticles. Color contrast observed on the surfaces is related to the presence of $\mathrm{Ag} / \mathrm{TiO}_{2}$ nanoparticles on those regions. Some agglomerates are observed in the sample containing $700 \mathrm{ppm}$ of $\mathrm{Ag} / \mathrm{TiO}_{2}$.

result shows a promising approach for the development of a new family of antimicrobial additives for plastics. There is undoubtedly a trend toward the use of more environmental friendly antimicrobials with low toxicity.Antimicrobials based on silver substances meet this favorable toxicity profile and can be used at relatively low concentrations on the surface of plastic, showing important advantages over agents that cannot make similar claims. 


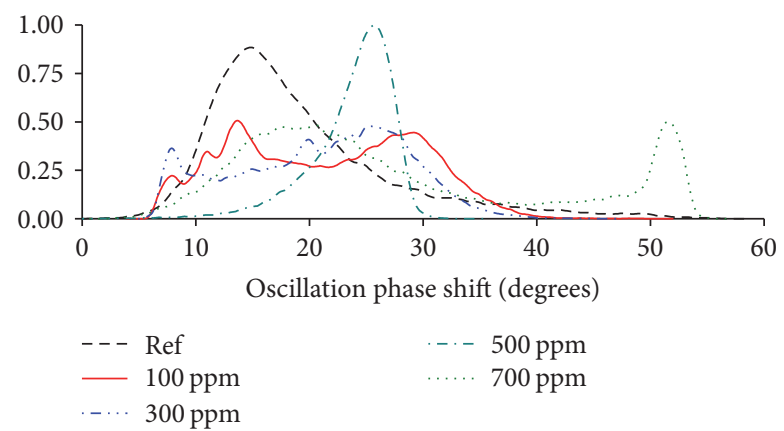

FIgure 4: Phase histogram of PS sample containing $\mathrm{Ag} / \mathrm{TiO}_{2}$ nanoparticles. Wide, bimodal histogram is observed for 100, 300, and $700 \mathrm{ppm}$ of $\mathrm{Ag} / \mathrm{TiO}_{2}$, showing the presence of PS and the additive. On the contrary, reference and the sample containing $500 \mathrm{ppm}$ of $\mathrm{Ag} / \mathrm{TiO}_{2}$ produce a unimodal distribution indicating that the additive homogenously covers the PS surface.

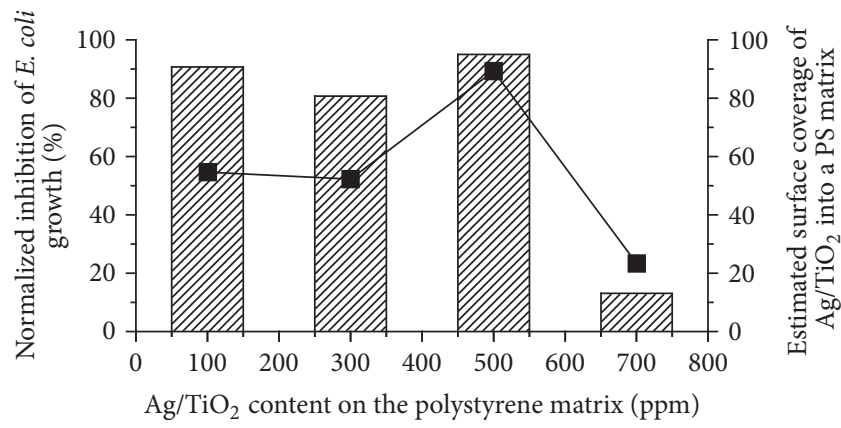

FIgURE 5: Antibacterial growth inhibition of polystyrene-based samples as $\mathrm{Ag} / \mathrm{TiO}_{2}$ concentration increases. Values are normalized with respect to a reference sample of pure polystyrene. Markers represent the estimated surface coverage of the $\mathrm{Ag} / \mathrm{TiO}_{2}$. The inhibition of E. coli growth is directly related to the surface coverage of $\mathrm{Ag} / \mathrm{TiO}_{2}$ on the PS surface.

\section{Competing Interests}

The authors declare that there is no conflict of interests regarding the publication of this paper.

\section{Acknowledgments}

The authors thank A. M. González-Amaro and M. L. RiveraMartínez for their help and advice concerning the antibacterial activity tests. They also thank J. L. Menchaca (Universidad Autónoma de Nuevo León) for AFM facilities. This project was partially financed by A. Schulman de Mexico S. A. de C.V.

\section{References}

[1] H. Zweifel, Plastic Additives Handbook, Hanser Gardner Publications, Munich, Germany, 2001.

[2] S. Ebnesajjad and K. Modjarrad, Handbook of Polymer Applications in Medicine and Medical Devices, Elsevier, 2013.

[3] I. Sondi and B. Salopek-Sondi, "Silver nanoparticles as antimicrobial agent: a case study on E. coli as a model for Gram- negative bacteria," Journal of Colloid and Interface Science, vol. 275, no. 1, pp. 177-182, 2004.

[4] C.-N. Lok, C.-M. Ho, R. Chen et al., "Proteomic analysis of the mode of antibacterial action of silver nanoparticles," Journal of Proteome Research, vol. 5, no. 4, pp. 916-924, 2006.

[5] H.-J. Park, J. Y. Kim, J. Kim et al., "Silver-ion-mediated reactive oxygen species generation affecting bactericidal activity," Water Research, vol. 43, no. 4, pp. 1027-1032, 2009.

[6] Q. L. Feng, J. Wu, G. Q. Chen, F. Z. Cui, T. N. Kim, and J. O. Kim, "A mechanistic study of the antibacterial effect of silver ions on Escherichia coli and Staphylococcus aureus," Journal of Biomedical Materials Research, vol. 52, no. 4, pp. 662-668, 2000.

[7] S.-Q. Sun, B. Sun, W. Zhang, and D. Wang, "Preparation and antibacterial activity of $\mathrm{Ag}-\mathrm{TiO}_{2}$ composite film by liquid phase deposition (LPD) method," Bulletin of Materials Science, vol. 31, no. 1, pp. 61-66, 2008.

[8] H. M. Sung-Suh, J. R. Choi, H. J. Hah, S. M. Koo, and Y. C. Bae, "Comparison of Ag deposition effects on the photocatalytic activity of nanoparticulate $\mathrm{TiO}_{2}$ under visible and UV light irradiation," Journal of Photochemistry and Photobiology A: Chemistry, vol. 163, no. 1-2, pp. 37-44, 2004.

[9] S. Rengaraj and X. Z. Li, "Enhanced photocatalytic activity of $\mathrm{TiO}_{2}$ by doping with $\mathrm{Ag}$ for degradation of 2,4,6trichlorophenol in aqueous suspension," Journal of Molecular Catalysis A: Chemical, vol. 243, no. 1, pp. 60-67, 2006.

[10] O. Akhavan, "Lasting antibacterial activities of $\mathrm{Ag}-\mathrm{TiO}_{2} / \mathrm{Ag} / \mathrm{a}-$ $\mathrm{TiO}_{2}$ nanocomposite thin film photocatalysts under solar light irradiation," Journal of Colloid and Interface Science, vol. 336, no. 1, pp. 117-124, 2009.

[11] Z. V. Quiñones-Jurado, M. Á. Waldo-Mendoza, H. M. AguileraBandin, E. G. Villabona-Leal, E. Cervantes-González, and E. Pérez, "Silver nanoparticles supported on $\mathrm{TiO}_{2}$ and their antibacterial properties: effect of surface confinement and nonexistence of plasmon resonance," Materials Sciences and Applications, vol. 5, no. 12, pp. 895-903, 2014.

[12] L. Prati and A. Villa, "The art of manufacturing gold catalysts," Catalysts, vol. 2, no. 1, pp. 24-37, 2011.

[13] S. Oros-Ruiz, J. A. Pedraza-Avella, C. Guzmán et al., "Effect of gold particle size and deposition method on the photodegradation of 4-chlorophenol by $\mathrm{Au} / \mathrm{TiO}_{2}$," Topics in Catalysis, vol. 54, no. 8-9, pp. 519-526, 2011.

[14] M. Haruta, "Size- and support-dependency in the catalysis of gold," Catalysis Today, vol. 36, no. 1, pp. 153-166, 1997.

[15] R. Zanella, S. Giorgio, C. R. Henry, and C. Louis, "Alternative methods for the preparation of gold nanoparticles supported on $\mathrm{TiO}_{2}$," Journal of Physical Chemistry B, vol. 106, no. 31, pp. 76347642,2002

[16] K. R. Souza, A. F. F. de Lima, F. F. de Sousa, and L. G. Appel, "Preparing $\mathrm{Au} / \mathrm{ZnO}$ by precipitation-deposition technique," Applied Catalysis A: General, vol. 340, no. 1, pp. 133-139, 2008.

[17] N. F. Martínez and R. García, "Measuring phase shifts and energy dissipation with amplitude modulation atomic force microscopy," Nanotechnology, vol. 17, no. 7, pp. S167-S172, 2006.

[18] R. Garcia, C. J. Gómez, N. F. Martinez, S. Patil, C. Dietz, and R. Magerle, "Identification of nanoscale dissipation processes by dynamic atomic force microscopy," Physical Review Letters, vol. 97, no. 1, Article ID 016103, 2006.

[19] Y. H. Liu, D. Wang, K. Nakajima et al., "Characterization of nanoscale mechanical heterogeneity in a metallic glass by dynamic force microscopy," Physical Review Letters, vol. 106, no. 12, Article ID 125504, 2011. 
[20] D. Wang, X.-B. Liang, Y.-H. Liu, S. Fujinami, T. Nishi, and K. Nakajima, "Characterization of surface viscoelasticity and energy dissipation in a polymer film by atomic force microscopy," Macromolecules, vol. 44, no. 21, pp. 8693-8697, 2011.

[21] P. K. Sahoo, S. S. Kalyan Kamal, T. J. Kumar, B. Sreedhar, A. K. Singh, and S. K. Srivastava, "Synthesis of silver nanoparticles using facile wet chemical route," Defence Science Journal, vol. 59, no. 4, pp. 447-455, 2009.

[22] M. Kamali, S. A. A. Ghorashi, and M. A. Asadollahi, "Controllable synthesis of silver nanoparticles using citrate as complexing agent: characterization of nanoparticles and effect of $\mathrm{pH}$ on size and cristallinity," Iranian Journal of Chemistry and Chemical Engineering, vol. 31, pp. 21-28, 2012.

[23] M. Vanaja, S. Rajeshkumar, K. Paulkumar, G. Gnanajobitha, C. Malarkodi, and G. Annadurai, "Kinetic study on green synthesis of silver nanoparticles using Coleus aromaticus leaf extract," Advances in Applied Science Research, vol. 4, pp. 50-55, 2013.

[24] X. Xu, Z. Zhang, and W. Liu, "Fabrication of superhydrophobic surfaces with perfluorooctanoic acid modified $\mathrm{TiO}_{2} /$ polystyrene nanocomposites coating," Colloids and Surfaces A: Physicochemical and Engineering Aspects, vol. 341, no. 1-3, pp. 21-26, 2009.

[25] T. P. Selvin, J. Kuruvilla, and T. Sabu, "Mechanical properties of titanium dioxide-filled polystyrene microcomposites," Materials Letters, vol. 58, no. 3-4, pp. 281-289, 2004.

[26] A. Chandra, L.-S. Turng, S. Gong, D. C. Hall, D. F. Caulfield, and H. Yang, "Study of polystyrene/titanium dioxide nanocomposites via melt compounding for optical applications," Polymer Composites, vol. 28, no. 2, pp. 241-250, 2007. 

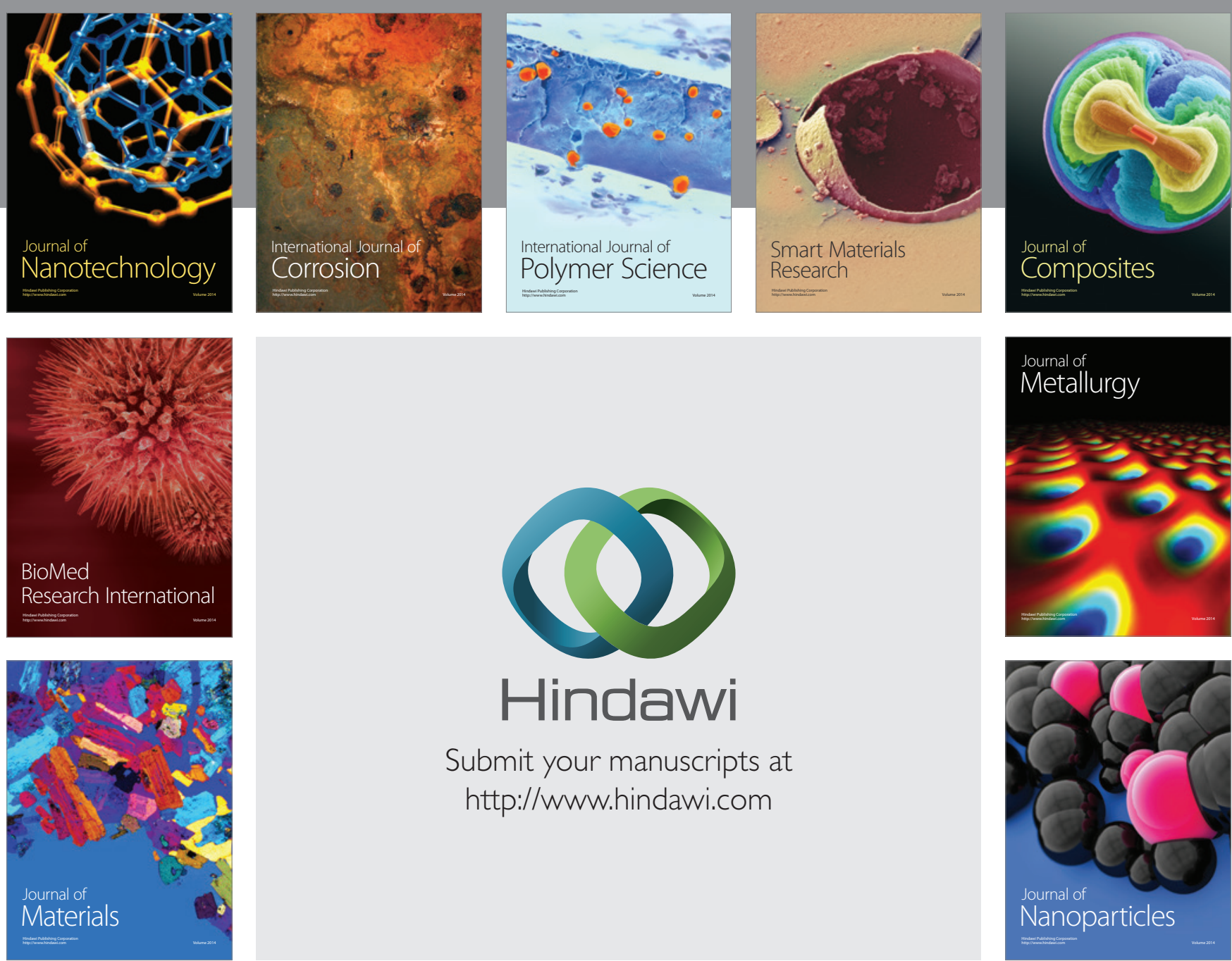

\section{Hindawi}

Submit your manuscripts at

http://www.hindawi.com

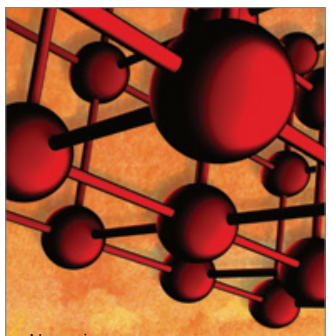

Materials Science and Engineering
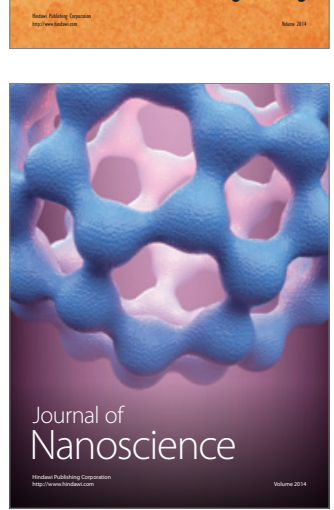
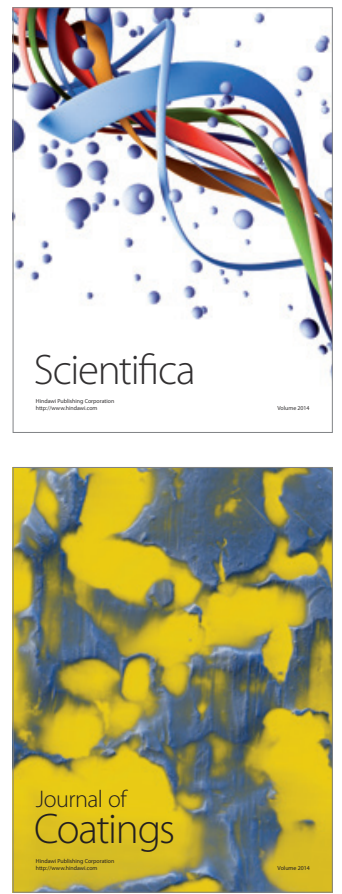
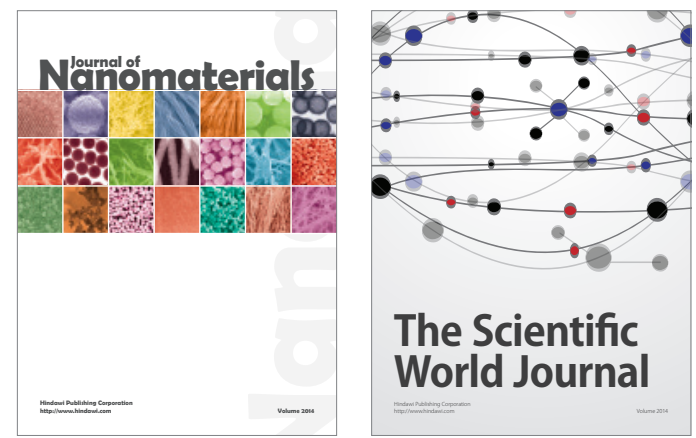

The Scientific World Journal
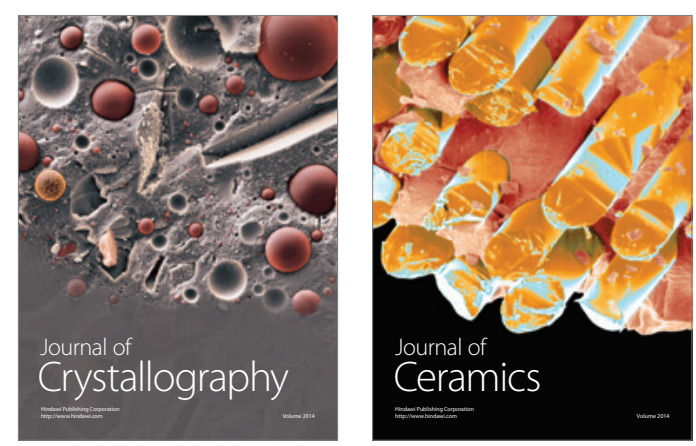
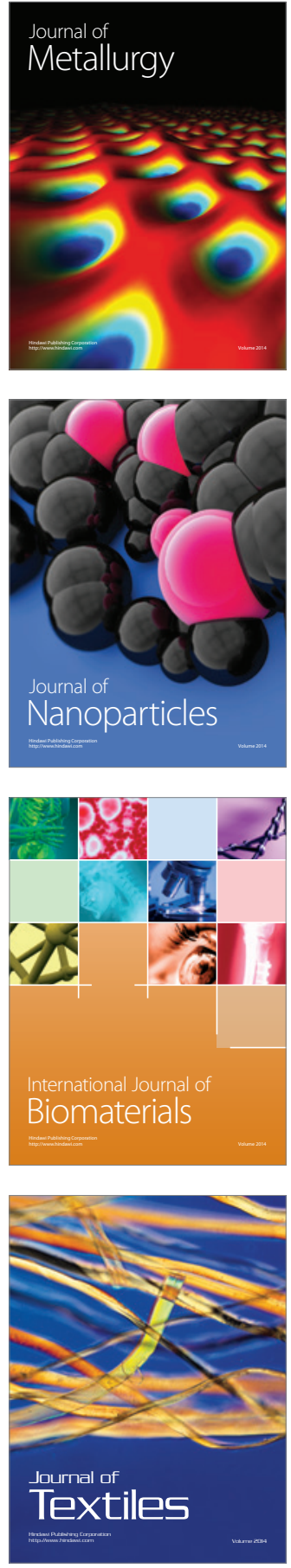